\title{
Foreign Capital, Inflation, Sterilization, Crowding-Out and Growth: \\ Some Illustrative Models
}

\author{
Nirvikar Singh ${ }^{+}$and T. N. Srinivasan*
}

\begin{abstract}
This paper discusses some puzzles in the contemporary macroeconomic scene in India, from the perspective of public finance and economic development. These include a fiscal deficit higher than it was during the 1991 crisis, but without a large current account deficit or rise in inflation or interest rates, a rising inflow of external capital, accompanied by the RBI's sterilizing these inflows and accumulating large reserves, even in the face of low inflation. We offer a critique of some previous analyses, and some models that are suggestive of how real and monetary factors might be integrated in providing a firmer grounding for the policy debates current in India.
\end{abstract}

Keywords: foreign capital, sterilization, absorption, crowding out, inflation, growth JEL codes: F30, F41, F43, H62, O4

\footnotetext{
${ }^{+}$Department of Economics and Santa Cruz Center for International Economics, University of California, Santa Cruz, CA 95064, boxjenk@ucsc.edu, Ph: (831) 459-4093

* Department of Economics and Economic Growth Center, Yale University, New Haven, CT 06520
} 


\title{
Foreign Capital, Inflation, Sterilization, Crowding-Out and Growth: Some Illustrative Models*
}

\author{
Nirvikar Singh and T. N. Srinivasan
}

May 2004

\section{Introduction}

The contemporary macroeconomic scene in India is a puzzle from the perspectives of public finance and development. Consider the following facts. First, the consolidated gross fiscal deficit (GFD) of central and state governments was 10.3\% of GDP in 2001-02, around $10.1 \%$ in 2002-03 according to revised estimates, and budgeted at 9.1\% in 2003-04 (RBI 2003, Table 2.23 and RBI 2004, Tables 2.19 and 2.26, allowing for consolidation of state and central budgets). The revised estimates for 2003-04 show that the central deficit has fortunately fallen from its budgeted value of $5.6 \%$ of GDP to $4.8 \%$, and it is budgeted to fall further to $4.4 \%$ in 2004-05 (Finance Minister's speech presenting the Interim Budget, February 3, 2004).

Nonetheless, even with this welcome fall, the consolidated GFD in 2003-04 is likely to exceed the $9.4 \%$ ratio to GDP reached in the crisis year, 1990-91. If we add net losses of public sector enterprises, off-budget items and the flow equivalent of contingent liabilities, the deficit figures will be much higher. The combined total debt of center and states was budgeted at $76.9 \%$ of GDP in 2003-04 in comparison to $61.7 \%$ in $1990-91$.

Second, and in contrast, external debt to national income fell from $28.7 \%$ in 1990 to $21.0 \%$ in 2001 , and the proportion of short-term to total external debt (to total gold and foreign

\footnotetext{
${ }^{*}$ We are grateful to Deepak Lal for very useful comments that helped us to clarify and sharpen our exposition. No doubt there are still shortcomings, and we alone are responsible for these. We also thank Marcy Kaufman for excellent assistance in preparing the manuscript.
} 
exchange reserves) also fell from $10.2 \%(365.4 \%)$ to $2.8 \%(5.4 \%)$ (RBI 2004, Tables 2.5, 7.12 and 7.14). The stock of reserves, which had hovered just about \$1 billion (less than two weeks worth of imports) between April and August of 1991 during the crisis, began its steady climb soon after. The rate of accumulation accelerated since 1999-2000, and the stock reached \$119 billion in early May 2004.

Third, the balance of payments on the current account has been in surplus, though by a small amount (less than $0.5 \%$ of GDP) for three years in succession starting in 2001-02. Fourth, annual growth rate of real GDP, having peaked at 7.8\% in 1996-97, has slowed down and fluctuated since then. It reached a low of $4.0 \%$ in the severe drought year of 2002-03 ('quick estimates'). The good monsoon in 2004 has led to a recovery and the advance estimate of the growth rate is $8.1 \%$ (CSO 2004). Even if an $8.1 \%$ growth rate is reached, a simple average growth rate during $1997-98$ to $2003-04$ will only be $5.6 \%$, as compared to an average of $6.7 \%$ during the first five years (1992-93 - 1997-98) after reforms were initiated. However, gross capital formation as a proportion of GDP in current (constant) prices averaged $24.8 \%(25.0 \%)$ in the first period and $23.8 \%(25.9 \%)$ in the second period. Thus, although real capital formation on an average was higher by nearly $2 \%$ in the second period, average growth was slower. Fifth, inflation rates, as measured by any of the price indices, have been low since the mid-nineties and so have interest rates.

Prima facie, these facts are puzzling. First, although the GFD is even higher than it was during the 1991 crisis, it has not been associated, as it was then, with a large current account deficit or rise in inflation or interest rates. Second, although some external credit rating agencies have downgraded Indian debt instruments to near junk bond status, such downgrading and the 
high fiscal deficit seem to have had little effect on the confidence of external investors; the inflow of external capital has been rising.

Third, running a current account surplus does not make sense since, as a developing country, presumably with opportunities for high yielding investments, India should be running a current account deficit financed by sustained capital inflows. Fourth, the RBI has been sterilizing foreign capital inflows and accumulating reserves to levels that prima facie appear too large relative to what would be needed to smooth shocks to export earnings and import expenditures and to provide (self) insurance against possible financial crisis, given that capital controls continue. ${ }^{1}$ Since inflation has been low by historical standards, sterilization for the purpose of containing inflationary pressures is not convincing. It is hard to say the rupee will appreciate to such an extent as to hurt exports in the short and medium run and to raise trade deficits. The fact that part of the reserves accumulated have been used to prepay debt suggests that the policy makers cannot see ways of investing these resources in the economy so as to earn a return higher than the rate of interest on debt. ${ }^{2}$

Fifth, reduction in financial repression and freeing of interest rates apparently have had little effect on household financial saving, which rose marginally from a simple average of 10.2\% of GDP at current prices during 1992-93 - 1996-97 to $10.8 \%$ during $1997-98$ to $2002-03$, while direct saving in the form of physical assets rose significantly from $8 \%$ of GDP to $10.7 \%$ during the same period. Given household savings are estimated as residuals and fluctuate quite a bit, we do not wish to overemphasize these differences. Still, it is a bit odd that savings in the

\footnotetext{
${ }^{1}$ An informal case for reserve accumulation based on self-insurance motives and for its signaling role is provided by Kapur and Patel (2003). Joshi and Sanyal (2004) appear to support this view, though they explicitly state that the reserves to imports ratio is now high enough (based on a rule of thumb argument) and should not be further increased.

${ }^{2}$ Joshi and Sanyal (2004, p. 34) implicitly assume something similar, when they state, "policymakers must urgently consider how to utilize the continuing inflows productively."
} 
form of physical assets went up and financial savings did not after the freeing of interest rates or deposits.

The recent literature has focused largely on three issues. The first is whether or not the current level of public debt is sustainable without a major fiscal correction, and the related one of apparent lack of signs of a looming financial crisis in spite of India's macroeconomic indicators being, in fact, similar to or worse than in those countries which did experience a crisis. The second is whether or not more productive private investment was crowded out by fiscal deficits. The third is whether instead of sterilizing external capital inflows and accumulating reserves, had the Reserve Bank of India (RBI) let the inflows be absorbed and rupee appreciate, would the growth rate of the economy have been significantly higher in the last few years. On the first issue, several papers were presented at a conference (January 15-16, 2004) sponsored by the National Institute for Fiscal Policy (NIPF) and the International Monetary Fund (IMF).

A paper by Lal, Bery and Pant (2003a), hereafter LBP, addresses the second and third issues. An earlier version, LBP (2003b) of the paper elicited a number of comments and the authors (LBP 2003c) have responded to their critics. LBP use essentially two models. The first is the so-called Australian Dependent Economy real model of a small open economy with three commodities (an exportable, an importable and a non-traded good, with the first two combined into a Hicksian composite traded good ${ }^{3}$ ) and two factors (capital and labour). The second is a model of Lal, Bhide and Vasudevan (2001) involving nominal variables, such as money supply

\footnotetext{
${ }^{3}$ For a small open economy, the world price of importable relative to that of exportable is determined in world markets and is assumed to be constant. The domestic relative price is also constant, given an ad valorem tariff on the importable. With relative prices constant, one can construct a Hicksian composite traded good using either the domestic or international relative price. The creation of the composite is unnecessary for algebraic analysis, but it is convenient for illustration through two-dimensional diagrams. However, in doing so, one has to be clear whether a unit of a domestic or world price-based composite is depicted on one of the axes.
} 
and nominal bonds. This model is not fully described in the paper. ${ }^{4}$ In addition, LBP invoke macroeconomic accounting identities. LBP go back and forth between real effects of alternative policies on growth and relative prices and nominal effects, such as on inflation, nominal exchange rates, price level, etc.

Unfortunately, the real and monetary models of LBP are not integrated. ${ }^{5}$ For example, the preferences of consumers in the real model depend only on their consumption of the two commodities, and their decisions regarding the demand for money and other nominal assets, including bonds, which presumably are features of the nominal model, apparently have no influence on these real consumption decisions. The real model is useful for comparing the real effects of absorbing or not absorbing the real inflow. But one cannot use it for comparing the effects of sterilizing inflows with those of not sterilizing them. These are policies that affect nominal variables of money supply and bonds. As we show in Section 2, incorporating consumer demand for money even in a very simple transactions-demand form makes a difference in determining how the decision to let real external flows be absorbed or not affects relative prices and inflation. We also argue below that sterilization is not equivalent to nonabsorption.

As we state in our paper (Singh and Srinivasan, 2004) for the NIPF-IMF conference, which drew upon other papers of the conference, one needs a coherent intertemporal model that incorporates the real and monetary sectors of the economy and that fits Indian data well for

\footnotetext{
${ }^{4}$ An earlier paper by Lal (1989) provides a model with real and monetary factors considered simultaneously. However, money demand in this model is not derived from any behavioral postulates. In fact, the demand for money appears to be an asset demand, requiring intertemporal considerations. This feature is combined with a static real model, but without allowing for real variables to affect money demand, as would happen in any integrated optimization model. Hence, this paper is subject to the same criticism as LBP.

${ }^{5} \mathrm{We}$ do not imply that other macroeconomic modeling in this vein is immune to this criticism: in fact, the problem may be quite pervasive, as suggested to us by Deepak Lal. Nevertheless, our focus in this paper is the Indian case, and LBP's work has been the focus of considerable attention. As we state later in this introduction, LBP's policy discussion remains valuable, despite our taking issue with aspects of the formal modeling.
} 
analyzing the puzzles noted above. No such model is available in the literature, nor did we provide one in our paper. Nevertheless, we argued that the facts are consistent with the climate for private corporate investment having worsened since 1996-97. Thus, a rise in the fiscal deficit and fall in interest rates and inflation are consistent with a rise in foreign capital inflow, unchanged or even a rise in household financial saving, and a fall in private investment. In this paper we develop some formal intertemporal models that begin to provide a coherent framework. A limitation remains in that we do not incorporate money into these intertemporal models: nevertheless, growth, investment and deficit issues can be more clearly analyzed along the lines that we present, than in past discussions of India's macroeconomic situation.

The structure of the paper is as follows. In Section 2, we re-examine the sterilization and absorption issues raised by LBP, in a more clearly specified monetary model, albeit a static one. In Section 3, we present several illustrative theoretical models, which examine growth, deficits and investment, without the complication of money. Section 4 concludes. We also discuss some additional analytical and empirical issues arising from the LBP paper, in Appendix 1.

Note that the models we present here may be helpful as coherent analytical foundations for a future econometric exercise. However, we should hasten to add that these models are very simple, and even simplistic, and address analytically only some, and not all, of the relevant issues. Our intention in presenting them is to encourage others to attempt building and estimating more satisfactory and complete models. Finally, many of our criticisms of LBP are applicable to much of the literature on the issues of crowding out, inflation and exchange rate effects of fiscal deficits and capital inflows. But these criticisms should in no way be deemed as our lack of appreciation of the LBP paper, particularly its section on policy implications, which we found to be very rich and informative. 


\section{Absorption, Sterilization and Crowding Out}

We noted earlier that the real and monetary models of LBP are not integrated, and the decisions of consumers regarding the demand for money and other nominal assets have no influence on their real consumption decisions. We show here that incorporating consumer demand for money makes a difference in determining the impacts on relative prices and inflation, of the decision to let real external flows be absorbed or not. We also argue that sterilization is not equivalent to non-absorption: the former is neutralizing the monetary impact of foreign capital inflows, and the latter is preventing their impact on real flows of goods. ${ }^{6}$

Our model with an explicit demand for money is based on a simple static version of the Australian dependent economy model used by LBP. It has three goods, an import good, an export good, and a non-traded good. The demand for money is determined as a proportional transaction demand, and is therefore tied to the real economy, as one would expect. ${ }^{7}$ There is no bond market, so sterilization of foreign inflows by selling bonds is not an option in this model. Indeed, this structure emphasizes our distinction between sterilization and non-absorption. We discuss sterilization separately, after analyzing the formal model.

\footnotetext{
${ }^{6}$ We make this point in the context of our behavioral model - a different point underlies Joshi and Sanyal's (2004) accounting-based critique of LBP's analysis of the growth costs of reserve accumulation. They note that sterilization over the period analyzed was far from complete, and that "Capital and remittance inflows were absorbed, except to the extent of (sterilized) foreign exchange accumulation." (p. 11) However, Joshi and Sanyal's treatment of monetary policy responses to inflows gets closer to our argument. See also the discussion in our Appendix 1.

${ }^{7}$ This is just one way in which money demand can be modeled. Two standard alternatives are to put money in the utility function, and to impose a cash-in-advance constraint. For example, van Wijnbergen (1991) uses the former strategy, in a model with a single consumption good, domestic money, and foreign bonds. There is no trade in real goods, and openness just impacts intertemporal consumption through borrowing and saving decisions. As an example of the latter approach, Burnside, Eichenbaum and Rebelo (2001) have a simple cash-in-advance constraint on consumption purchases, and this is very similar in effect to a transaction demand as we model it. Their model is also one with a single consumption good, and intertemporal allocation, with openness just allowing borrowing and lending. Thus, there is no real trade in either model. In contrast, our model is static, but allows for trade in real goods, as does the model of LBP. Unlike LBP or Lal (1989), we relate the demand for money to nominal expenditures, and do not graft on a separate intertemporal model in our illustrative exercise. To this extent, our model is more coherent and integrated than LBP's.
} 
For simplicity, suppose there is no domestic production (consumption) of an import substitute (export good). The economy is a small open economy, which takes world prices (normalized to unity, in some world numéraire, say, dollars, by choice of units of measurement) as parametrically given. Then, under free trade, the prices in domestic currency (rupee) of a unit of the export good and the import good equal $e$, the nominal exchange rate (rupees per dollar).

Let $p_{N}$ be the domestic currency price of the non-traded good. Let $\bar{F}$ be the vector of inelastically supplied domestic factors of production. Let factors be internationally immobile. Then under profit maximization and pure competition we can write the supply functions $S_{X}$ and $S_{N}$ of the export and non-traded good respectively as $S_{X}\left(\frac{e}{p_{N}} ; \bar{F}\right)$ and $S_{N}\left(\frac{e}{p_{N}} ; \bar{F}\right)$. The domestic demand $D_{I}$ and $D_{N}$ for the imported and non-traded good respectively as $D_{I}\left(\frac{e}{p_{N}}, \frac{E}{p_{N}}\right)$ and $D_{N}\left(\frac{e}{p_{N}}, \frac{E}{p_{N}}\right)$ where $E$ is total expenditure on commodities in rupees.

Demand for money $M^{d}$ in this economy is for transactions only so that

$$
M^{d}=\lambda E
$$

Suppose the private sector of this economy receives a gift of $G$ dollars from abroad. ${ }^{8}$ Consider two alternative ways, A and B, of using this gift.

A: Government buys the dollar gift from the private sector at the going exchange rate $e$, with newly created money, and adds $G$ dollars to its reserves (in other words, $G$ is not absorbed). B: The private sector uses $G$ dollars to buy import good, i.e., $G$ is absorbed.

In Case A, the money supply $M$ in the economy goes up by $e G$ and the dollars to buy imports are generated by sale of exports. In Case B, money supply remains at its pre-gift level

\footnotetext{
${ }^{8}$ We will treat external capital inflow as a gift in this paper so that we can ignore the debt service (profit repatriation) implications of foreign borrowing (direct and portfolio investment).
} 
$\bar{M}$, but the finance for imports goes up by $G$ dollars over export earnings. The market equilibrium conditions in the two cases $(i=\mathrm{A}, \mathrm{B})$

Money Market

$$
\begin{aligned}
& M_{i}^{d}=\lambda E_{i} \\
& M_{i}^{s}=\bar{M}+\theta_{i} e G
\end{aligned}
$$

where $\theta_{A}=1$ and $\theta_{B}=0$

$$
M_{i}^{d}=M_{i}^{s}
$$

$\underline{\text { Market for imports }}$

$$
D_{I}\left(\frac{e}{p_{N}}, \frac{E_{i}}{p_{N}}\right)=S_{X}\left(\frac{e}{p_{N}} ; \bar{F}\right)+\omega_{i} G
$$

where $\omega_{A}=0$ and $\omega_{B}=1$

Market for non-traded good

$$
D_{N}\left(\frac{e}{p_{N}}, \frac{E}{p_{N}}\right)=S_{N}\left(\frac{e}{p_{N}} ; \bar{F}\right)
$$

Now, including its expenditure on acquisition of money, the total expenditure of the private sector (for simplicity, there is no taxing or spending by the government) is $(1+\lambda) E_{i}$ :

Resources available for financing this expenditure is the sum of initial money stock $\bar{M}$ and income from sales of the output of the export and non-trade goods (as well as the gift $G$ ). Equating total expenditure with resources available for financing it we get:

$$
\begin{array}{r}
(1+\lambda) E_{i}=\bar{M}+e S_{X}+p_{N} S_{N}+e G \\
E_{A}=e S_{X}+p_{N} S_{N} \\
E_{B}=e\left(S_{X}+G\right)+p_{N} S_{N}
\end{array}
$$

Since $E_{i}$ is also the expenditure on the imported and non-traded good, we get:

$$
E_{i}=e D_{I}+p_{N} D_{N}, i=A, B
$$


Equations (2.8), (2.9), and (2.5) imply (2.6). This is nothing but Walras Law. Thus, we need only two market equilibrium conditions, say (2.4) and (2.5).

Consider Case A. Denote $\frac{e}{p_{N}}$, the real exchange rate, i.e., the relative price of either traded good in terms of the non-traded goods as $e_{R}$. Denote the real expenditure $\frac{E_{A}}{p_{N}}=E_{R A}$.

Then from (2.5) we have

$$
D_{I}\left(e_{R A}, E_{R A}\right)=S_{X}\left(e_{R A} ; \bar{F}\right)
$$

$$
\begin{aligned}
& \text { Now } \frac{\partial D_{I}}{\partial e_{R A}}<0, \frac{\partial D_{I}}{\partial E_{R A}}>0 \text { (imports are normal goods) and } \frac{\partial S_{X}}{\partial e_{R A}}>0 \text {. Thus: } \\
& \frac{\partial D_{I}}{\partial e_{R A}} \cdot \frac{\partial e_{R A}}{\partial E_{R A}}+\frac{\partial D_{I}}{\partial E_{R A}}=\frac{\partial S_{X}}{\partial e_{R A}} \cdot \frac{\partial e_{R A}}{\partial E_{R A}}
\end{aligned}
$$

so that

$$
\frac{\partial e_{R A}}{\partial E_{R A}}=\frac{\partial D_{I}}{\partial E_{R A}} /\left(\frac{\partial S}{\partial e_{R A}}-\frac{\partial D_{I}}{\partial e_{R A}}\right)>0
$$

From (2.2) and (2.4) we get:

$$
\lambda E_{A}=\bar{M}+e G
$$

so that

$$
\lambda \frac{E_{A}}{p_{N A}}=\frac{\bar{M}}{p_{N A}}+\frac{e}{p_{N A}} G
$$

Denoting $\bar{M}_{R A}$ as real money stock and $E_{R A}$ as real expenditure (both in terms of nontraded goods), we get

$$
\lambda E_{R A}=\bar{M}_{R A}+e_{R A} G
$$

Dividing both sides of (2.8A) by $p_{N}$ we get: 


$$
E_{R A}=e_{R A} S_{X}\left(e_{R A} ; \bar{F}\right)+S_{N}\left(e_{R A} ; \bar{F}\right)
$$

Thus (2.5) and (2.8A) $)^{\prime}$ together yield the equilibrium values $e_{R A}^{*}$ and $E_{R A}^{*}$ as functions of $\bar{F}$.

Note that neither depends on $G$ since in Case A, the gift $G$ is not absorbed.

Using these in (2.14), we solve for the equilibrium real money stock $\bar{M}_{R}^{*}$ as

$$
\bar{M}_{R A}^{*}=\lambda E_{R A}^{*}-e_{R A}^{*} G
$$

The nominal prices in equilibrium then follow as:

$$
\begin{gathered}
p_{N A}^{*}=\frac{\bar{M}}{\bar{M}_{R A}^{*}} \\
e_{A}^{*}=p_{N A}^{*} e_{R A}^{*}=\frac{\bar{M}}{\bar{M}_{R A}^{*}} \cdot e_{R A}^{*}
\end{gathered}
$$

We note from (2.16) and (2.17) that nominal prices are proportional to the initial money stock $\bar{M}$. Now $\frac{\partial \bar{M}_{R A}^{*}}{\partial G}=-e_{R A}^{*}<0$ so that nominal prices are increasing functions of the foreign gift $G$. However, since $e_{R A}^{*}$ and $E_{R A}^{*}$ are functions only of $\bar{F}$ and not of $G$, relative price of the traded good and real expenditure are unaffected by $G$. Thus, as long as the government adds the gift $G$ to its reserves, and does not allow it to be absorbed in the economy, there is no real production, consumption, trade or welfare effect of the gift on the economy and there is only an inflationary effect. ${ }^{9}$

Now consider Case B. Dividing both sides of (2.8B) by $p_{N}$ we get:

$$
E_{R B}=e_{R B}\left(S_{X}+G\right)+S_{N}
$$

Equation (2.5) in this case is:

\footnotetext{
${ }^{9}$ One might phrase this as a case of nominal absorption without any real absorption, and the outcome is obvious once the model is written down and analyzed completely. Conflating these two possibilities seems to a source of confusion in some of this literature.
} 


$$
D_{I}\left(e_{R B} ; E_{R B}\right)=S_{X}\left(e_{R B}, \bar{F}\right)+G
$$

Equations (2.2) and (2.4) yield:

$$
\begin{gathered}
\lambda E_{B}=\bar{M} \quad \text { or } \\
\lambda E_{R B}=\bar{M}_{R B}
\end{gathered}
$$

Now (2.5)" and (2.8)" together solve for equilibrium value $e_{R B}^{*}$ and $E_{R B}^{*}$. However, unlike in Case A, they are now functions both of $\bar{F}$ and $G$. However, $\bar{M}_{R B}$ is not a function of $G$. The nominal values $e_{B}^{*}$ and $p_{N B}^{*}$ are:

$$
\begin{gathered}
p_{N B}^{*}=\frac{\bar{M}}{\lambda E_{R B}^{*}} \\
e_{B}^{*}=p_{N B}^{*} e_{R B}^{*}=\frac{\bar{M}}{\lambda} \frac{e_{R B}^{*}}{E_{R B}^{*}}
\end{gathered}
$$

Once again, the nominal values are proportional to $\bar{M}$.

Since the gift $G$ adds to the supply of imports as well as to the total expenditure of imports and non-traded goods, it has both a substitution effect in domestic production towards non-traded goods and real expenditure effects. Naturally, the full impact on the equilibrium real exchange rate $e_{R B}^{*}$ and real expenditure on $E_{R B}^{*}$ would depend on various demand and supply elasticities as well as the size of the gift $G$. From (2.5)", it follows that:

$$
\frac{\partial D_{I}}{\partial e_{R B}} \cdot \frac{\partial e_{R B}^{*}}{\partial G}+\frac{\partial D_{I}}{\partial E_{R B}} \cdot \frac{\partial E_{R B}^{*}}{\partial G}=\frac{\partial S_{X}}{\partial e_{R B}} \cdot \frac{\partial e_{R B}^{*}}{\partial G}+1
$$

Let $(i)-\frac{e_{R B}}{D_{I}} \cdot \frac{\partial D_{I}}{\partial e_{R B}} \equiv \alpha \equiv$ absolute value of the elasticity of demand for imports with respect to $e_{R B}$. Clearly, it is positive. 
(ii) $\frac{E_{R B}}{D_{I}} \frac{\partial D_{I}}{\partial E_{R B}} \equiv \beta \equiv$ elasticity of demand for imports with respect to real expenditure $E_{R B}$. Clearly, this is positive as long as imports are normal goods.

(iii) $\frac{e_{R B}}{S_{E}} \cdot \frac{\partial S_{\gamma}}{\partial e_{R B}} \equiv \gamma=$ elasticity of the supply of exports with respect to its real price $e_{R B}$.

This can be assumed to be positive.

(iv) $\frac{G}{e_{R B}^{*}} \frac{\partial e_{R B}^{*}}{\partial G} \equiv \delta=$ elasticity of equilibrium real exchange rate with respect to $G$. Its sign is to be determined in equilibrium.

(v) $\frac{G}{E_{R B}^{*}} \frac{\partial E_{R B}^{*}}{\partial G} \equiv \eta=$ elasticity of equilibrium real expenditure with respect to $G$. Its sign is to be determined in equilibrium.

(vi) $\frac{-e_{R B}}{S_{N}} \frac{\partial S_{N}}{\partial e_{R B}} \equiv \varepsilon \equiv$ the absolute value of the elasticity of the supply of non-traded goods with respect to the real exchange rate. It can be assumed to be positive.

Rewrite (2.18) as:

$$
\begin{gathered}
-\frac{D_{I}}{G} \alpha \delta+\frac{D_{I}}{G} \beta \eta=\frac{S_{X}}{G} \gamma \delta+1 \text { or } \\
\delta=\frac{\left(\frac{D_{I}}{G} \beta \eta-1\right)}{\frac{\alpha D_{I}}{G}+\frac{\gamma S_{X}}{G}}
\end{gathered}
$$

The denominator of $(2.18)^{\prime}$ is positive. Since $D_{I}=S_{X}+G, \frac{D_{I}}{G}>1$. By assumption $\beta>0$ and if imports are elastic with respect to real expenditure, $\beta>1$. Thus, if $\eta$, the elasticity of equilibrium real expenditure is positive and not too low $\delta>0$ so that the real exchange rate 
depreciates. If $\eta \leq 0$, then $\delta<0$ and the real exchange rate appreciates. However $\eta$, being an equilibrium value, has to be solved for and substituted in (2.18) for determining the effect of the absorption of the gift on the real exchange rate.

Differentiating (2.8)" with respect to $G$

$$
\begin{aligned}
\frac{\partial E_{R B}^{*}}{\partial G}= & \frac{\partial e_{R B}^{*}}{\partial G}\left(S_{X}+G\right)+e_{R B}^{*}\left(\frac{\partial S_{X}}{\partial e_{R B}^{*}} \cdot \frac{\partial e_{R B}^{*}}{\partial G}+1\right)+\frac{\partial S_{N}}{\partial e_{R B}^{*}} \cdot \frac{\partial e_{R B}^{*}}{\partial G} \quad \text { or } \\
\frac{E_{R B}^{*}}{G} \eta= & \frac{e_{R B}^{*}}{G} \delta\left(S_{X}+G\right)+e_{R B}^{*}\left(\frac{S_{X}}{e_{R B}^{*}} \gamma \cdot \frac{\delta}{G} e_{R B}^{*}+1\right)-\frac{S_{N}}{e_{R B}^{*}} \varepsilon \cdot \frac{e_{R B}^{*}}{G} \cdot \delta \quad \text { or } \\
& -\delta\left[e_{R B}^{*}\left\{\left(S_{X}+G\right)+\gamma S_{X}\right\}-\varepsilon S_{N}\right]+E_{R B}^{*} \eta=e_{R B}^{*} G
\end{aligned}
$$

Now, since $S_{X}$ and $S_{N}$ maximize $e_{R B}^{*} S_{X}+S_{N}$, it follows that:

$$
\begin{gathered}
e_{R B}^{*} \frac{\partial S_{X}}{\partial e_{R B}^{*}}+\frac{\partial S_{N}}{\partial e_{R B}^{*}}=0 \quad \text { or } \\
\gamma S_{X}-\frac{S_{N} \varepsilon}{e_{R B}^{*}}=0
\end{gathered}
$$

Using (2.20) in (2.19), we get:

$$
-\delta e_{R B}^{*}\left(S_{X}+G\right)+E_{R B}^{*} \eta=e_{R B}^{*} G
$$

Substituting for $\delta$ from (2.18)' in (2.22), we get:

$$
\begin{gathered}
-\frac{e_{R B}^{*}\left(S_{X}+G\right) \cdot\left(\frac{D_{I}}{G} \beta \eta-1\right)}{\left(\frac{\alpha D_{I}}{G}+\frac{\gamma S_{X}}{G}\right)}+E_{R B}^{*} \eta=e_{R B}^{*} G \quad \text { or } \\
\eta\left[E_{R B}^{*}-\frac{\left(\frac{\beta D_{I}}{G}\right)\left(S_{X}+G\right) e_{R B}^{*}}{\frac{\alpha D_{I}}{G}+\frac{\gamma S_{X}}{G}}\right]=e_{R B}^{*} G-\frac{e_{R B}^{*}\left(S_{X}+G\right)}{\alpha \frac{D_{I}}{G}+\gamma \frac{S_{X}}{G}}
\end{gathered}
$$




$$
\eta\left[\left(\frac{\alpha D_{I}}{G}+\gamma \frac{S_{X}}{G}\right) E_{R B}^{*}-\left(\frac{\beta D_{I}}{G}\right)\left(S_{X}+G\right) e_{R B}^{*}\right]=\left\{G\left(\frac{\alpha D_{I}}{G}+\frac{\gamma S_{X}}{G}\right)-\left(S_{X}+G\right)\right\} e_{R B}^{*}
$$

Using (2.5)" and (2.8)" in (2.22), we get:

$$
\begin{gathered}
\eta\left[\left(\frac{\alpha D_{I}}{G}+\frac{\gamma S_{X}}{G}\right)\left\{e_{R B}^{*}\left(S_{X}+G\right)+S_{N}\right\}-\frac{\beta D_{I}}{G}\left(S_{X}+G\right) e_{R B}^{*}\right] \eta=\left\{(\alpha-1)\left(S_{X}+G\right)+\gamma S_{X}\right\} e_{R B}^{*} \quad \text { or } \\
{\left[\left\{(\alpha-\beta) \frac{D_{I}}{G}+\gamma \frac{S_{X}}{G}\right\} e_{R B}^{*}\left(S_{X}+G\right)+\left(\frac{\alpha D_{I}}{G}+\frac{\gamma S_{X}}{G}\right) S_{N}\right] \eta=\left[(\alpha-1)\left(S_{X}+G\right)+\gamma S_{X}\right] e_{R B}^{*}}
\end{gathered}
$$

Thus:

$$
\eta=\frac{\left[(\alpha-1)\left(S_{X}+G\right)+\gamma S_{X}\right] e_{R B}^{*}}{\left[\left\{(\alpha-\beta) \frac{D_{I}}{G}+\frac{\gamma S_{X}}{G}\right\}\left(S_{X}+v\right) e_{R B}^{*}+\left(\frac{\alpha D_{I}}{G}+\frac{\gamma S_{X}}{G}\right) S_{N}\right]}
$$

Substituting for $\eta$ from (2.23) in (2.18)', we get:

$$
\begin{aligned}
& \delta=\frac{\left[\left(\beta \frac{D_{I}}{G}\right)(\alpha-1)\left(S_{X}+G\right) \gamma S_{X}\right] e_{R B}^{*}-\left[\left\{(\alpha-\beta) \frac{D_{I}}{G}+\gamma \frac{S_{X}}{G}\right\}\left(S_{X}+G\right) e_{R B}^{*}+\left(\frac{\alpha D_{I}}{G}+\frac{\gamma S_{X}}{G}\right) S_{N}\right]}{\left[\frac{\alpha D_{I}}{G}+\gamma \frac{S_{X}}{G}\right]\left[\left\{(\alpha-\beta) \frac{D_{I}}{G}+\gamma \frac{S_{X}}{G}\right\}\left(S_{X}+G\right) e_{R B}^{*}+\left(\frac{\alpha D_{I}}{G}+\frac{\gamma S_{X}}{G}\right) S_{N}\right]} \\
& =\frac{\left[\left\{\alpha(\beta-1) \frac{D_{I}}{G}\left(S_{X}+G\right)-\gamma S_{X}\right\} e_{R B}^{*}-\left(\frac{\alpha D_{I}}{G}+\frac{\partial S_{X}}{G}\right) S_{N}\right]}{\left[\frac{\alpha D_{I}}{G}+\gamma \frac{S_{X}}{G}\right]\left[\left\{(\alpha-\beta) \frac{D_{I}}{G}+\gamma \frac{S_{X}}{G}\right\}\left(S_{X}+G\right) e_{R B}^{*}+\left(\frac{\alpha D_{I}}{G}+\frac{\gamma S_{X}}{G}\right) S_{N}\right]}
\end{aligned}
$$

Clearly if $\beta<1$ and $\alpha>\beta$, then $\delta<0$. Thus, if the demand for imports is inelastic with respect for real expenditure and the price elasticity of import demand exceeds its real expenditure elasticity, then $\delta<0$ or the real exchange rate appreciates as the gift $G$ is absorbed. On the other hand, if $\alpha>\operatorname{Max}(1, \beta)$, it follows from (2.23) that $\eta>0$ but the sign of $\delta$ is ambiguous. Thus, unlike the case of no absorption of the gift in which the gift has only an inflationary effect, full absorption of the gift has ambiguous real (and also nominal) effects in general. The precise 
effect becomes an empirical issue, depending on the magnitude of various demand elasticities. Thus we have shown that incorporating money into the real Australian model, even in a static framework, changes some aspects of the analysis significantly. The real and nominal aspects of the economy cannot first be analyzed in isolation and then combined ex post.

Turning to the nature of sterilization and its impact on crowding out, note that LBP compare monetization of fiscal deficits with sterilization of capital inflows, and claim that "as with capital inflow that is sterilized, a fiscal deficit that is not monetized will leave the real exchange rate unchanged, but reduce investment, the growth of the capital stock, and the growth rate" (LBP 2003, p. 4967). This is misleading. An exogenous foreign gift adds to the resources available to the economy. Sterilization is equivalent to two operations by the RBI: first, it purchases the gift with money creation, and then it absorbs the newly created money through the sale of government securities it owns. ${ }^{10}$ Sterilization thus affects the composition of the RBI's balance sheet (i.e., it swaps its domestic assets in the form of government securities for foreign assets of equal value). Government securities are liabilities of the government regardless of whether they are held by RBI or others to whom RBI sells them. As such, in a consolidated balance sheet of the government and RBI, liabilities are unaffected by the swap, and the asset side is larger by the amount of the foreign gift. If the RBI did not sterilize its newly created money, its non-interest bearing currency liabilities would go up by the value of foreign gift it buys. In a consolidation, non-interest bearing liabilities and assets go up by the same amount. Leaving aside the sources of fiscal deficit, its financing by monetization adds to noninterest bearing liabilities of the government, while bond-financing adds to its interest bearing liabilities. But there is no change in assets, as in the case of a foreign gift. However, by

\footnotetext{
${ }^{10}$ Note particularly that in the formal model considered earlier in this section, the second step is not available to the government. In case A of that analysis, money is injected into the economy through the government's purchase of the gift, but this has no real effect, only a nominal impact.
} 
assuming that fiscal deficit results in an increase in the current account deficit, which is financed by a reduction in foreign currency reserves in the case of its monetization, LBP in effect reduce the money supply, thus swapping what otherwise would have been an increase in domestic liabilities to an equivalent decrease in foreign assets. On the other hand, if the private savingsinvestment balance shifts to accommodate the fiscal deficit, this swap need not occur. In any case, since there is no net addition to assets regardless of the mode of financing the fiscal deficit, comparison of financing deficits with sterilization or otherwise of capital inflow is inappropriate. Bond financing leads to crowding out of private investment in the LBP analysis, while monetization of deficits does not. This is presumably because in the latter case, the assumed mode of adjustment to fiscal deficits is a fall in reserves and not in the private savingsinvestment balance, whereas in the former case, it is the private savings-investment balance that adjusts. Hence, the growth effects of alternative ways of financing differ because of this assumption. In the case of capital inflows, the growth or welfare effects differ depending on whether the inflow is absorbed or not, and not from whether it was sterilized.

In any case, the issue of absorption of capital inflow is, in principle, separable from the issue of sterilization. Absorption involves the use of the additional resources from the inflow for financing additional imports. In the real model, in the case in which the government "buys" the inflow through a tax transfer and "stores" it, no additional imports come in. But, if instead one were to assume that the government uses the inflow it bought for public consumption, and if the government's utility function were the same as that of the private sector, the equilibrium would be the same as if the government did not buy the inflows. Going beyond the model, the government's prepayment of part of its external debt from reserves can be viewed as absorption: instead of absorbing it so as to raise domestic investment (i.e., increase domestic assets 
regardless of whether they are privately or publicly owned), it reduced its external debt. If the return on domestic investment is no higher than that on foreign debt, such absorption is appropriate.

\section{Growth, Investment and Deficits}

In this section, we illustrate the analytics of fiscal deficits and their financing, crowding out, savings and investment through a series of four growth models. Unlike the static model considered in Section 2, there is no money in these models. This allows us to focus on the growth and deficit implications of different assumptions on savings and investment behavior. The central point is that growth and government deficits are both determined endogenously by more fundamental assumptions on savings and investment behavior. It is precisely such features that are absent from models such as those of van Wijnbergen (1991) and Burnside, Eichenbaum and Rebelo (2001), ${ }^{11}$ which consider intertemporal consumption and foreign borrowing, but without any role for either private or public investment. This modeling strategy appears to be quite common, allowing consideration of some implications of fiscal deficits, but not those highlighted in our models.

\section{Model I}

This is a Harrod-Domar model with firms, households and government. Subscripts used are 'g' for 'government', 'p' for private sector', and ' $h$ ' for 'households'. Only households save, while the private sector and government both invest. The behavioral equations and equilibrium are quite simple. $Y$ stands for GDP, and there is no interest rate. Savings are a constant fraction of GDP, and the sign and magnitude of $\lambda$ in the private investment demand equation reflect

\footnotetext{
${ }^{11}$ See footnote 7 for a brief discussion of these two papers.
} 
whether, and the extent to which, public investment crowds in or crowds out private investment. The parameters $\beta_{p}$ and $\beta_{g}$ are the constant marginal products of capital, or reciprocals of the sectoral ICORs, and $\mathrm{K}_{\mathrm{p}}$ and $\mathrm{K}_{\mathrm{g}}$ are the corresponding capital stocks.

$$
\begin{array}{ll}
\text { Savings } & S=s_{h} Y \\
\text { Private Investment Demand } & I_{p}=\lambda I_{g}+\mu Y \\
\text { Investment Finance } & S \\
\text { Investment Equilibrium } & I_{p}+I_{g}=S \\
\text { Solving these equations: } & I_{g}=\left[\left(s_{h}-\mu\right) /(1+\lambda)\right] Y \\
\text { and } & I_{p}=\left[\lambda\left(s_{h}-\mu\right) /(1+\lambda)+\mu\right] Y
\end{array}
$$

We assume that $s_{h}-\mu>0$, or the marginal propensity to save out of income exceeds the private marginal propensity to invest. This ensures that government investment is positive in the above equilibrium. Note that here government investment passively soaks up savings not absorbed by the private sector.

$$
\text { Output is given by } \quad Y=\beta_{p} K_{p}+\beta_{g} K_{g}
$$

Hence, the equilibrium growth rate is

$$
\begin{aligned}
g & =\left(\beta_{p} I_{p}+\beta_{g} I_{g}\right) / Y \\
& =\left[\beta_{p}\left(\lambda s_{h}+\mu\right)+\beta_{g}\left(s_{h}-\mu\right)\right] /(1+\lambda)
\end{aligned}
$$

Finally,

$$
\partial g / \partial \lambda=\left(\beta_{p}-\beta_{g}\right)\left(s_{h}-\mu\right) /(1+\lambda)^{2}
$$

As long as $\beta_{p}>\beta_{g}$, and given $s_{h}-\mu>0$, the last expression is positive, as one would expect. In fact, as $\lambda \rightarrow \infty, I_{g} \rightarrow 0$ and $g \rightarrow \beta_{p} s_{h}$, which is the maximal growth rate.

To relate this model to the issue of crowding out effects of fiscal deficits, note that the government deficit in the model is given by 


$$
D=I_{g}-T
$$

where $T$ is tax revenue, and is simply a transfer from households to the government. If $T=0$, then the deficit is simply the government's investment. In that case, equation (3.5) is also the government deficit in equilibrium. Both the deficit and the growth rate are determined endogenously, and what is relevant for determining their correlation is the movement of the underlying parameters. Thus, an increase in $\lambda$ reduces the deficit, but increases the growth rate. On the other hand, an increase in $s_{h}$ increases private and public investment and, hence, the growth rate in equilibrium. However, since public investment is the same as the deficit, an increase in $s_{h}$ increases the deficit.

If $T>0$, it may be more realistic to model saving as coming out of disposable income. Furthermore, we can assume that tax revenue has some buoyancy with respect to income: this is captured by the parameter $b$, so that $T=b Y$. Our savings equation is modified as follows.

Savings

$$
S=s_{h}(Y-T)=s_{h}(1-b) Y \equiv s_{h} Y
$$

Thus, the parameter $s_{h}$ is simply replaced by $s_{h}{ }^{\prime}$ in the remaining equations of the model. In this case, an increase in taxation, through an increase in b, simply reduces growth, because it reduces savings. At the same time, the equilibrium deficit is now given by

$$
D=\left[\left(s_{h}{ }^{\prime}-\mu\right) /(1+\lambda)-b\right] Y
$$

Thus, the equilibrium deficit and the growth rate both decrease as $b$ increases.

\section{Model II}

The above model lacks an interest rate mechanism for equilibrating savings and investment. Equilibrium is achieved through adjustments in government investment. Government investment expenditure crowds in through a technological assumption $(\lambda>0)$, but 
there is no crowding out. Our second model is essentially a modification of the first that introduces the interest rate, and hence the possibility of endogenous crowding out. We allow somewhat more general functional forms.

$$
\begin{array}{ll}
\text { Savings } & S=S(r, Y), \text { where } S_{r}>0, S_{Y}>0 \\
\text { Private Investment Demand } & I_{p}=f\left(I_{g}\right) I(r), \text { where } f^{\prime}>0, I^{\prime}<0 \\
\text { Investment Finance } & S(r, Y) \\
\text { Investment Equilibrium } & f\left(I_{g}\right) I(r)+I_{g}=S(r, Y)
\end{array}
$$

Since $\mathrm{Y}$ is predetermined, (3.4)"determines combinations of $I_{g}$ and $r$ that are consistent with equilibrium. $I_{g}$ can now be exogenous, with the interest rate serving to equilibrate savings and investment. Given the assumed standard responses of savings and investment to interest rate movements, it is easy to show that $\partial r / \partial I_{g}>0$, so that greater government investment is associated with higher interest rates. This represents the conventional crowding out effect.

$$
\text { In fact, } \quad \partial r / \partial I_{g}=\left[f^{\prime} I(r)+1\right] /\left[S_{r}-f\left(I_{g}\right) I^{\prime}\right]
$$

Hence, the growth rate is

$$
\begin{aligned}
& g=\left(\beta_{p} I_{p}+\beta_{g} I_{g}\right) / Y \\
& \quad=\left[\beta_{p}\left(S(r, Y)-I_{g}\right)+\beta_{g} I_{g}\right] / Y \\
& Y \partial g / \partial I_{g}=-\left(\beta_{p}-\beta_{g}\right)+\beta_{p} S_{r} \partial r / \partial I_{g}
\end{aligned}
$$$$
\text { or using (3.4)" }
$$

In this case, we see that the growth implications of an increase in government investment are ambiguous, and depend on the relative efficiency of public and private investment, and the responses of savings and investment to interest rates, as well as the magnitude of any crowding in. Note that taxation in this model may now reduce crowding out, by reducing the government's net demand for investment funds. This is in addition to the previous effect of reducing savings. This adds another complication to the impact of government investment on growth. 


\section{Model III}

We extend the previous approach by allowing for optimal savings and taxation, using a neoclassical model with two types of capital (public and private). This allows for a richer analysis. The labor force grows exogenously at the rate $n$, and the production function exhibits constant returns to scale. Public investment in this model is financed entirely by capital taxation, so there is no deficit: debt financing is considered in the next model.

The social planner maximizes

$$
\int_{0}^{\infty} e^{-\rho t} u(c(t)) d t
$$

subject to

$$
\begin{aligned}
& \dot{k}_{p}=[1-\tau(t)] f\left[k_{p}(t), k_{g}(t)\right]-n k_{p}(t)-c(t) \\
& \dot{k}_{g}=\tau(t) f\left[k_{p}(t), k_{g}(t)\right]-n k_{g}(t) \\
& \text { and } 0 \leq \tau \leq 1
\end{aligned}
$$

where $c(t)$ : per worker consumption

$k_{p}(t), k_{g}(t):$ per worker capital stocks

$\tau(t):$ proportionate tax on capital

Maximizing the current value Hamiltonian

$$
H=u(c)+\lambda\left[(1-\tau) f=n k_{p}-c\right]+\mu\left[\tau f-n k_{g}\right]
$$

with respect to the control variable $c$ and $\tau$, we have the first order conditions

$$
\begin{aligned}
& \partial H / \partial c=0 \Rightarrow u^{\prime}=\lambda \\
& \frac{\partial H}{\partial \tau}=(-\lambda+\mu) f
\end{aligned}
$$

Since $f>0, \tau=0(1)$ if $\mu<(>) \lambda$ and $0 \leq \tau \leq 1$ if $\mu=\lambda$ 
From (3.15) and (3.16) it follows that

$$
\dot{k}_{g}\left(\dot{k}_{p}\right)<0 \text { if } \tau=0(1)
$$

The equations of motion for the costate variables $\lambda$ and $\mu$ are:

$$
\begin{aligned}
& \dot{\lambda}=\lambda \rho-\partial H / \partial k_{p}=\lambda \rho-\left[\{\lambda(1-\tau)+\mu \tau\} \partial f / \partial k_{p}-n \lambda\right] \\
& \dot{\mu}=\mu \rho-\partial H / \partial k_{g}=\mu \rho-\left[\{\lambda(1-\tau)+\mu \tau\} \partial f / \partial k_{g}-n \mu\right]
\end{aligned}
$$

If $\lambda=\mu$ during any interval of time, then $\dot{\lambda}=\dot{\mu}$, so that (3.20) and (3.21) imply $\frac{\partial f}{\partial k_{p}}=\frac{\partial f}{\partial k_{g}}$, i.e., the marginal product of either type of capital is the same. This suggests (assuming $\frac{\partial^{2} f}{\partial k_{p} \partial k_{g}}>0$, i.e., marginal product of either capital rises as the stock of the other capital rises $^{12}$ ) that along an optimal path, if at $t=0, \frac{\partial f}{\partial k_{p}}>\frac{\partial f}{\partial k_{g}}$, then $\dot{k}_{p}>0$ and $\dot{k}_{g}<0$ (i.e., $\tau=0$ and $\lambda>\mu$ ) until such time when $\frac{\partial f}{\partial k_{p}}$ equals $\frac{\partial f}{\partial k_{g}}$. Similarly, $\dot{k}_{p}<0$ and $\dot{k}_{g}>0$ (i.e., $\tau=1$ and $\lambda<\mu)$ if initially $\frac{\partial f}{\partial k_{p}}<\frac{\partial f}{\partial k_{g}}$. Thus, except for an initial interval of time, $\lambda=\mu$ and $\frac{\partial f}{\partial k_{p}}=\frac{\partial f}{\partial k_{g}}$

Along a steady state, noting that $\lambda=\mu$, one obtains

$$
\begin{aligned}
& \partial f\left(k_{p}^{*}, k_{g}^{*}\right) / \partial k_{p}=\partial f\left(k_{p}^{*}, k_{g}^{*}\right) / \partial k_{g}=n+\rho \\
& c^{*}=f\left(k_{p}^{*}, k_{g}^{*}\right)-n\left[k_{p}^{*}+k_{g}^{*}\right]
\end{aligned}
$$

\footnotetext{
${ }^{12}$ This is analogous to the crowding in assumption in the first model, since a rise in public capital increases the marginal product of private capital, and hence encourages private investment.
} 


$$
\tau^{*}=n k_{g}^{*} / f\left(k_{p}^{*}, k_{g}^{*}\right)
$$

Thus we derive the optimal investment and consumption paths, as well as the associated optimal tax rate for financing public investment. As is the case with neoclassical optimal growth models of this genre, the steady state levels of consumption, outputs, capital-labor ratios and the tax rates depend only on the pure rate of time preference and the rate of growth of the labor force. Preferences and initial capital stocks matter only along the transition to the steady state.

\section{Model IV}

In this case, Model III is altered by replacing tax finance with debt finance. The steady state results are very similar, as one might expect. We will abbreviate the notation slightly where it is obvious. Here $d$ is the debt stock of the government per worker, $r$ is the interest rate on debt, and $-s$ is debt service (i.e., interest due on existing debt $(r d) \underline{\text { minus any gross additions }}$ $\dot{d}+n d$ to debt per worker or equivalently, plus any gross repayment of debt per worker.

The equations of motion are

$$
\begin{aligned}
& \dot{k}_{p}=f\left[k_{p}(t), k_{g}(t)\right]-n k_{p}(t)-c(t)-s \\
& \dot{k}_{g}=s-n k_{g}(t) \\
& \dot{d}=s+(r-n) d
\end{aligned}
$$

Once again, maximizing the current value Hamiltonian

$$
H=u(c)+\lambda \dot{k}_{p}+\mu \dot{k}_{g}+v \dot{d}
$$

with respect to the control variables $c$ and $s$, we have the first order conditions

$$
\partial H / \partial c=0 \Rightarrow u^{\prime}=\lambda
$$




$$
\frac{\partial H}{\partial s}=(-\lambda+\mu+v)
$$

so that $s \rightarrow-\infty$ if $\lambda>\mu+v$

$$
\begin{gathered}
\rightarrow+\infty \text { if } \lambda<\mu+v \\
-\infty \leq-s \leq+\infty \text { if } \lambda=\mu+v
\end{gathered}
$$

Thus, for $s$ to be finite, $\lambda=\mu+v$ for all $t$, which in turn implies $\dot{\lambda}=\dot{\mu}+\dot{v}$.

The equations of motion for the three costate variables $\lambda, \mu, v$ are:

$$
\begin{aligned}
& \dot{\lambda}=\lambda \rho-\partial H / \partial k_{p}=\lambda \rho-\lambda\left[\partial f / \partial k_{p}-n\right] \\
& \dot{\mu}=\mu \rho-\partial H / \partial k_{g}=\mu \rho-\lambda \partial f / \partial k_{g}+n \mu \\
& \dot{v}=v \rho-\partial H / \partial d=v[\rho-r+n]
\end{aligned}
$$

Taking (3.31) $-(3.33)$ together with $\lambda=\mu+v$ for all $t$, yields:

$$
\lambda\left(\frac{\partial f}{\partial k_{p}}-\frac{\partial f}{\partial k_{g}}\right)=v r \quad \text { or } \quad \frac{\partial f}{\partial k_{p}}=\frac{\partial f}{\partial k_{g}}+\frac{v r}{\lambda}
$$

One can interpret this as follows: suppose we increase $s$ by $\varepsilon$ by reducing $\dot{k}_{p}$ by $\varepsilon$ so that $k_{p}$ falls by $\varepsilon d t$. This costs $\frac{\partial f}{\partial k_{p}} \cdot \varepsilon d t$ in terms of rate of output. An increase of $s$ by $\varepsilon$ raises $\dot{k}_{g}$ by $\varepsilon$ and $k_{g}$. It also increases $\dot{d}$ by $\varepsilon$ and debt $d$ by $\varepsilon d t$. The gain from the latter two increases in terms of rate of output are $\frac{\partial f}{\partial k_{g}} \cdot \varepsilon d t$ and $\frac{v r}{\lambda} \cdot \varepsilon d t$. Along the optimal path, the cost of raising $s$ by $\varepsilon d t$ and the gain from it have to be equal and this is what 3.34 implies.

Consider the case where $r>n+\rho$. Then $v \rightarrow 0$ as $t \rightarrow \infty$. Then it is clear that in the steady state (i.e., $\dot{\lambda}=\dot{\mu}=0$ ) 


$$
\rho+n=\partial f / \partial k_{p}=\partial f / \partial k_{g}
$$

as in the tax financed case.

$$
\text { If } r<n+\rho \text {, then } v \rightarrow \infty \text { if } v_{0} \neq 0 \text {. }
$$

Ruling out $v=0$ for all $t$, the transversality condition requires

$$
\lim _{t \rightarrow \infty} v d(t)=0
$$

so that

$$
\lim _{t \rightarrow \infty} d(t)=0 \text { since }|v| \rightarrow \infty
$$

Note that Models III and IV can be viewed as models of a small open economy that faces unchanging world relative prices of commodities and interest rates. In Model III, $f$ represents the maximized value at world prices of domestic output per worker, given $k_{p}$ and $k_{g}$. With the normalization that world prices of all commodities are unity, the addition of (3.14) and (3.15) implies that trade is balanced so that there is no international borrowing or lending. Model IV differs from Model III is that international borrowing or lending at the world interest rate $r$ is allowed. $^{13}$

Model IV could also be used to illustrate the implications of a gift $z$ (in terms of world numéraire per worker per instant) to the private sector of the economy. ${ }^{14}$ Assume that $z$ is received either for a finite period $0 \leq t \leq T$ (Case A) or permanently, i.e., for all $t \geq 0$ (Case B). In effect, the gift adds $z$ to the value of output per worker, i.e., $f\left(k_{p}, k_{g}\right)$ at world prices. Thus (3.25) is changed to:

\footnotetext{
${ }^{13}$ To see this, suppose that all borrowing is from abroad. Now $s$ is net receipts (new borrowing minus interest payments) from abroad, calculated per worker. Let $m$ be the value of imports per worker and $x$ be the value of exports per worker, both at world prices. Then gdp + imports $\equiv$ consumption + investment + exports or:

$f+m=c+\left(\dot{k}_{p}+\dot{k}_{g}\right)+n\left(k_{p}+k_{g}\right)+x$, or current account deficit $\equiv m-x=-f+c+\dot{k}_{p}+\dot{k}_{g}+n\left(k_{p}+k_{g}\right)=s=$ capital account surplus. A full open economy version of the model, with both domestic and foreign borrowing can also be developed. See Appendix 2.

${ }^{14}$ In the context of macroeconomic policy for India, the gift can be interpreted as remittances from abroad.
} 


$$
\dot{k}_{p}=z+f\left(k_{p}, k_{g}\right)-n k_{p}-c-s
$$

for $0 \leq t \leq T$ in Case A and for all $t \geq 0$ in Case B. The other constraints, (3.26) and (3.27), remain the same.

Suppose the optimal choice of time paths for the control variables $c$ and $s$ for the case of no gift (i.e., $z=0$ for all $t \geq 0$ ) are $c^{\circ}$ and $s^{\circ}$, with the associated values for the costate variables being $\lambda^{\circ}, \mu^{\circ}$ and $v^{\circ}$. It is easy to see that a choice of $\hat{c}=c^{\circ}+z$ and $\hat{s}=s_{0}$ (for either $0 \leq t \leq T$ in Case A or for all $t \geq 0$ in Case B) with nothing else changed is feasible. With such a choice, it is easily seen that $\hat{k}_{p}=k_{p}^{\circ}, \hat{k}_{g}=k_{g}^{\circ}$ and $\hat{d}=d^{\circ}$. Clearly, such a choice is not optimal: were it to be optimal, a path $\hat{\lambda}=u^{\prime}(\hat{c})$ for the costate variable has to satisfy its equation of motion

$$
\dot{\hat{\lambda}}=-\hat{\lambda}\left[\frac{\partial f}{\partial k_{g}}-(n+\rho)\right]
$$

Obviously, with $\hat{k}_{g}=k_{g}^{\circ}$ and $k_{p}=\hat{k}_{p}^{\circ}, \hat{\lambda}$ cannot satisfy this equation: if it did, $u^{\prime}(\hat{c}) \equiv \hat{\lambda}=\lambda^{\circ} \equiv u^{\prime}\left(c^{\circ}\right)$, which is not possible, as long as $z \neq 0$ and $u(-)$ is strictly concave. Since such a policy is feasible, an optimal policy will yield a higher intertemporal welfare. Thus, a policy of keeping $k_{p}, k_{g}, d$ along their path of the case $z=0$ for $t \geq 0$ and adding the gift entirely to consumption is not optimal and yields a lower welfare.

Consider an alternative policy of reducing debt accumulation, taxing away the reduction in debt service (i.e., prepayment of debt), and using the tax receipts for replacing debt-financed accumulation of public debt. That is, let:

$$
\begin{gathered}
\hat{s}=s^{\circ}-\tau \\
\dot{\hat{k}}_{p}=z+f-n \hat{k}_{p}-\hat{c}-\tau-\hat{s}
\end{gathered}
$$




$$
\begin{aligned}
& \dot{\hat{k}}_{g}=\tau+\hat{s}-n \hat{k}_{g} \\
& \dot{\hat{d}}=\hat{s}+(r-n) \hat{d}
\end{aligned}
$$

where $\tau$ is the lump sum tax per worker.

It is obvious that $\hat{c}=c^{\circ}+z, \hat{k}_{p}=k_{p}^{\circ}, \hat{k}_{g}=k_{g}^{\circ}, \hat{d}=d^{\circ}-\tau \int_{0}^{t} e^{(r-n)} d t^{(u-t)}$ satisfy (3.38) $-(3.43)$, and hence, such a policy is feasible (for sufficiently small $\tau$ so that $\hat{d} \geq 0$ ). Once again, it is not optimal so that using the gift to reduce debt service yields lower intertemporal welfare than an optimal policy. It follows that in general, an optimal response to the gift, whether temporary or permanent, is to use it in part to raise consumption and in part to accumulate private or public capital as well as to prepay debt. It is clear that if the gift is temporary, the steady state output and consumption are unaffected (see equation (3.35)), and if the gift is permanent, the gift adds to the value of output for all $t \geq 0$, and in the steady state it will be added to consumption, since equation (3.35) implies that steady state capital stocks $k_{p}^{*}, k_{g}^{*}$ are unaffected. Thus, there is no presumption that a foreign inflow will all be absorbed as additional domestic investment. Note that, even if foreign inflows are earmarked for investment, domestic actors can engage in substitution according to their preferences. This sort of analysis is missing from the LBP modeling.

\section{Conclusion}

In this paper, we have argued that, in order to understand some of the puzzles in India's current macroeconomic situation, a coherent intertemporal model is required, in which both private and public savings and investment behavior are behaviorally specified, and growth, government deficits, and other macroeconomic variables are determined in equilibrium. We have 
also argued that if money is included in the model, which is required if one wishes to examine issues connected to sterilization of foreign inflows, it must be incorporated in a manner that recognizes interactions with the real side.

We have illustrated the importance of coherent intertemporal modeling, as well as properly incorporating money, in separate illustrative models. Our goal has been to provide some starting points for further theoretical analysis, which could then be used for empirical work that could have policy relevance. Since much of the policy debate on India's fiscal deficits, exchange rate management policy, and reserves management policy is either model-free, or uses ad hoc models, we believe that even our simple, illustrative models have some value in guiding future academic and policy discussion of India's macroeconomic situation. In this respect, we are in agreement with the approach of Joshi and Sanyal (2004), who use a Mundell-Fleming model to provide an analytical basis for assessing India's current macroeconomic situation and policy responses. Since the focus of the Mundell-Fleming model is on short run equilibria in goods, money and foreign exchange markets, our main focus on intertemporal models and growth can be seen as a complement to Joshi and Sanyal's work, though we overlap in our treatment of several analytical and policy issues.

\section{$\underline{\text { References }}$}

Burnside, Craig, Martin Eichenbaum and Sergio Rebelo (2001), 'Prospective Deficits and the Asian Currency Crisis,' Journal of Political Economy, Vol. 109 (6), pp. 1155-1197.

Kapur, Devesh, and Urjit R. Patel (2003) 'Large Foreign Currency Reserves: Insurance for Domestic Weakness and External Uncertainties?' Economic and Political Weekly, Vol. 38(11), pp.1047-53. 
Joshi, Vijay, and Sanjeev Sanyal (2004) 'Foreign Inflows and Macroeconomic Policy in India,' paper presented at NCAER/Brookings Conference in New Delhi, 26-28 March.

Lal, Deepak (1989) 'A Simple Framework for Analyzing Various Real Aspects of Stabilisation and Structural Adjustment Policies,' Journal of Development Studies, Vol. 25(3), pp. 291-313.

Lal, Deepak, Suman Bery and Devendra Kumar Pant (2003a) 'The Real Exchange Rate, Fiscal Deficits and Capital Flows -- India: 1981-2000', Economic and Political Weekly, Vol. 38, No. 47, November 22, pp 4965-4976.

Lal, Deepak, Suman Bery and Devendra Kumar Pant (2003b) 'The Growth Slowdown: Real Exchange Rate Misalignment, Fiscal Deficits and Capital Flows', NCAER, New Delhi (mimeo), www.ncaer.org/Upload/others/87/growth.pdf.

Lal, Deepak, Suman Bery and Devendra Kumar Pant (2003c) 'The Growth Slowdown - A Reply to Our Critics', NCAER, New Delhi (mimeo), www.ncaer.org/Upload/others/90/Slowdown.pdf.

Lal, Deepak, S. Bhide and D. Vasudevan (2001) 'Financial Exuberance: Savings Deposits, Fiscal Deficits and Interest Rates in India', Economic and Political Weekly, Vol. 36, No. 44, November 3, pp 4196-4203.

Singh, Nirvikar and T.N. Srinivasan (2004) 'Fiscal Policy in India: Lessons and Priorities,' forthcoming in NIPFP-IMF conference volume edited by Peter Heller.

van Wijnbergen, Sweder, 1991, "Fiscal Deficits, Exchange Rate Crises, and Inflation," Review of Economic Studies, Vol. 58 (1), pp. 81-92. 


\section{Appendix 1 - LBP Analysis: A Critique}

As we have discussed in the main paper, LBP use essentially two models, the Australian Dependent Economy real model of a small open economy, and a model involving nominal variables. Furthermore, we noted that the real and monetary models of LBP are not integrated. A second problem with their approach, as they themselves recognize, is that they do not have a full-fledged intertemporal model for the choice of paths of consumption, savings and investment (i.e., portfolio decision relating to the choice among real and nominal assets). For example, they are aware that accounting identities equating current account surplus with the excess of savings over investment, and with the change in net foreign assets less capital inflows, in and of themselves cannot tell anything about adjustments to, say, an exogenous change in capital inflows. What, among an infinite number of combinations of savings, investment, exports, imports, remittances, etc., needed to accommodate the change in capital inflows would be chosen cannot be inferred from the identities. One needs an intertemporal model integrating nominal and real decisions and which obviously has relevant interest and discount rates (not to mention stochastic shocks) to do a satisfactory analysis. Without such a model, LBP in effect assume particular combinations of adjustment. Naturally, they disavow anything other than illustrative significance to their empirical exercise. In our view, leaving aside several problems with the empirics, including their regressing one endogenous variable (the real exchange rate) on another (excess demand), the problem is much deeper. It is the lack of coherence between nominal and real models and the absence of a forward-looking framework for intertemporal decisions.

A third and last problem is that although the models are meant to illustrate the choice among alternative government policies of sterilization, bond financing and monetization, etc., 
LBP do not specify a government objective function describing the trade off among different consequences (i.e., inflation, crowding out, growth) of alternative policy choices. This is understandable given the fact government objective functions specified in various political economy models of the literature are crude!

Turning to the Australian model, there is a relatively minor error in the discussion by LBP of the model and its illustration in their Figure $\mathrm{I} .{ }^{15}$ As long as there is a non-zero tax or subsidy on traded goods, their domestic prices and world prices would differ, and the consumption point will not be on the production possibility frontier, since consumption expenditures would differ from the value of output by the net revenue from trade taxes or subsidies, LBP do not allow for this fact. ${ }^{16}$ We do so in our Figure 1, which assumes, for simplicity only, that the export (import) good is not consumed (produced) at home. Without loss of generality, the relative price of imports in terms of exports in world markets is assumed to be unity by choice of units of measurement of the two commodities. Assume that there is an ad valorem tariff at the rate $t$ on imports. One could have equivalently assumed an ad valorem tax on exports, as we know from the Lerner symmetry theorem. Let the non-taxed export good be the numéraire. At the initial equilibrium, output of non-traded goods is $N_{0}$ and of exports $X_{0}^{w}$. Under balanced trade at world prices, exports of $X_{0}^{w}$ buys $M_{0}^{w}=X_{0}^{w}$ of imports. In the domestic market price of non-tradables (i.e., relative price of non-tradables in terms of export good) is $\frac{O Y_{0}}{O Y_{0}^{\prime}}$ and that of import goods is $\frac{O E_{0}}{O E_{0}^{\prime}}=(1+t)$. At $S_{0}$ the domestic production possibility frontier $P_{0} P_{0}^{\prime}$ (relating efficient production of exportable to non-tradables) is tangential to

\footnotetext{
${ }^{15}$ As we note in the introduction, this error does not affect the value of the policy discussion in LBP.

${ }^{16}$ Also, they depict the capital inflow as a parallel shift in the budget line, thus measuring it in units of domestic price based composite of traded goods. This does not square with the balance of trade constraint that the inflow enables the economy to finance more imports at world prices than it earns from its exports, again at world prices.
} 
domestic price line $Y_{0} Y_{0}^{\prime}$. With trade balanced, the output of exports $\left(X_{0}^{w}\right)$ associated with $S_{0}$ is traded at world relative prices for $M_{0}^{w}=X_{0}^{w}$ units of imports. The demand $D_{0}$ then is the same as the supply at $S_{0}$ in physical units. From a consumer utility maximization perspective, the indifference curve through $D_{0}$ touches the price line for consumers, $E_{0} E_{0}^{\prime}$, which has a slope of the domestic relative price of non-tradables in terms of imports. This depiction of equilibrium assumes that the tariff revenue $Y_{0} E_{0}$ in terms of exports is returned to consumers in a lump sum fashion so that consumer expenditure $O E_{0}$ exceeds their factor income $O Y_{0}$ by the amount of tariff revenue.

Suppose now private consumers in the economy receive a gift of $F$ units in terms of exports. If the domestic relative price of non-tradable (the export real exchange rate) is unchanged, production will continue to be at $D_{0}$, but consumers now have $M_{0}^{w}+F$ to spend on imports so that supply point shifts to $S_{1}$. However, if the tariff rate remains unchanged, the relative price of importable will not change, and if preferences are homothetic, the demand point will move $\hat{D}_{1}$ on the ray from the origin $O$ connecting it to $D_{0}$. Thus, comparing $S_{1}$ with $\hat{D}_{1}$, there is an excess demand for non-tradables and an excess supply of non-tradables. With the tariff rate remaining at $t$, for bringing about an equilibrium, the relative price of non-tradables has to increase, so that both the export and import real exchange rates appreciate by the same proportion. Clearly, consumer welfare at the new equilibrium will be higher than at the initial equilibrium, assuming that both goods are normal in consumption. This is the case, to use the LBP terminology, of full absorption in the domestic economy of the gift $F$. LBP talk about alternative mechanisms for bringing about such an equilibrium, such as a rise in the nominal price of non-tradable or a rise in the nominal exchange rate. There are no nominal variables in 
this model. As such, these mechanisms are not applicable. In any case, the analysis being comparative-static, i.e., comparison of two equilibria, the question of dynamic mechanisms for moving from one equilibrium to the other is left open. For example, a Walrasian auctioneer could be added and the standard relative price adjustment story can be told. But no nominal magnitudes would be involved in the story.

We noted earlier that in the real model there can be no analogue of sterilization of the monetary impact of the gift through an open market operation using nominal bonds. However, the model is eminently suitable for analyzing policies relating to the absorption of the gift. For example, the government can prevent its absorption by imposing real taxation, as LBP recognize. Imagine that the government, instead of returning tariff revenue in a lump fashion to consumers, uses a part of it to buy $F$ at the initial domestic price of imports, which is in fact their opportunity cost to consumers (if the cost of $F$ exceeds tariff revenue, the balance is made up by lump sum taxation). The net effects of this operation are two (i) the government acquires $F$, which is no longer available to buy imports (ii) consumers on the one hand receive $(1+t) F$ from their sale of $F$ to government, but lose a part of the lump sum transfers they originally received or all of it and pay additional lump sum taxes. But, and this is the important point, this operation of tax-transfer leaves consumers at their original expenditure line $E_{0} E_{0}^{\prime}$ so that they consume at $D_{0}$. Thus, government gets $F$ (and adds it on to reserves) and production, consumption as well as relative prices remain at their initial equilibrium values. It is evident that in this static real model, not allowing the external gift to be absorbed has the effect of keeping welfare at its initial level and not letting it rise.

While the Australian model focuses on the role of real exchange rates as an equilibrating variable, these rates are strictly not necessary for a discussion of the welfare implications of 
absorption. For this purpose, the conventional two traded goods model will do. However, in such a model, the relative price of importable in terms of exportable does not change whether or not the gift is absorbed. The reason is that, for a small open economy, the world relative price is given and does not change, and the domestic relative price does not change either, given the unchanged tariff. Thus, in Figure 2, the initial production point is at $S_{0}$ where the domestic tariff inclusive relative price line $P^{d} P^{d^{\prime}}$. A gift $F$ shifts supply at unchanged domestic prices to $S_{1}$ and demand to $D_{1}$ (given homothetic tastes) where $S_{1}$ and $D_{1}$ are on the world price lines $\tilde{P}^{w} \tilde{P}^{w^{\prime}}$, which is parallel to $\tilde{P}^{w} \tilde{P}^{w^{\prime}}$. This is the case of full absorption. Welfare at $D_{1}$ is higher than at $D_{0}$. The government can prevent absorption by using all, as in the earlier case, or part of tariff revenue and any additional lump sum taxes to buy $F$ at domestic prices, leaving consumers at the initial equilibrium $D_{0}$. Once again, preventing absorption precludes a rise in welfare.

Clearly, the static version of the Australian real model is not suitable for deriving growth implications of not absorbing the gift and sterilization. LBP use an ad hoc procedure of assuming, for illustrative purposes, that the part of capital inflow that is allowed to be absorbed in any year will be added to investment that year and hence raise the capital stock the next year. This is somewhat puzzling - if the consumer's budget line is shifted by the full value of inflow absorbed, as LBP seem to be doing in their Figure 1, there cannot be any increase in investment due to the absorbed inflow. In any case, their assumption does not allow the differences in the time path of the real exchange rates (depending on whether inflows are being sterilized) to influence consumption and investment decisions. 


\section{$\underline{\text { Empirical estimates }}$}

It is difficult to evaluate the empirical estimates of LBP — for example, the description of the static model in their Appendix II (A) does not make clear whether the variables are in logarithms or absolute values — since the difference $P N-P T$ in equation A.1 makes sense only if $P N$ and $P T$ represent the logarithm of the price of non-traded and traded goods. Whereas in the growth case (their Appendix II (B)), both labor and capital are factors of production, in Appendix II (A) the wage rate enters the supply equation for non-tradables but not the rental rate for capital. In a two commodity model with inelastically supplied factors, it is enough to have relative commodity prices and aggregate factor endowments in the supply equations. But LBP do not take that route. In any case, unless some restrictions are placed on the parameters $a_{0}, a_{1}$. $\ldots b_{0}, b_{1} \ldots$ equations A1 to A7 would not be mutually consistent. Finally, in equation A1 for the demand for non-traded goods, money supply relative to money demand appears. It is hard to see the reason why it appears only in the demand for non-traded good. Again, since LBP seem to combine a real and monetary model without integrating them and it is also hard to see how the extent of crowding out of private investment was estimated, we cannot evaluate whether the illustrative numbers follow from a logically coherent set up. In addition to these points, we note that Joshi and Sanyal (2004) have argued that the LBP method for estimating forgone investment is logically flawed. Thus, even though the authors stress that their empirical exercise is only illustrative, it may be somewhat misleading overall.

\section{$\underline{\text { Appendix 2: Model IV with Foreign and Domestic Debt }}$}

Foreign debt can be accommodated by extending Model IV. We do so first in absolute terms, and then in per worker terms. In the following, we view the government as financing its 
investment by borrowing $B^{D}$ in the domestic capital market and $B^{F}$ from the foreign capital market, at an interest rate $r$ (which is viewed as administratively set in a pure domestic debt context or by world capital market, if there is foreign borrowing) and taxing the private sector an amount $T$ for interest payments $r\left(D^{D}+D^{F}\right)$ on domestic $\left(D^{D}\right)$ and foreign $\left(D^{F}\right)$ debt. Interest on domestic debt accrues as income to the private sector which also finances the government's domestic borrowing. Thus:

$$
\begin{gathered}
B^{D}+\dot{K}_{p}=F+r D^{D}-T-C \\
\dot{K}_{g}=B^{D}+B^{F} \\
T=r\left(D^{D}+D^{F}\right) \\
\dot{D}^{D}=B^{D}+r D^{D} \\
\dot{D}^{F}=B^{F}+r D^{F}
\end{gathered}
$$

Eliminating $T$ using (3) in (1) we get:

$$
B^{P}+\dot{K}^{P}=F-C-r D^{F}
$$

In per worker terms, these can be written as:

$$
\begin{gathered}
\dot{k}_{p}=f-c-r d^{F}-b^{D}-n k_{p} \\
\dot{k}_{g}=b^{D}+b^{F}-n k_{g} \\
\dot{d}^{D}=b^{D}+(r-n) d^{D}
\end{gathered}
$$




$$
\dot{d}^{F}=b^{F}+(r-n) d^{F}
$$

It is clear that if there is no foreign borrowing so that $d^{F}=b^{F}=0$ for all $t$, the model reduces to Model IV once one sets $s=b^{D}$. One can write the relevant Hamiltonian and do the optimization for the case with foreign and domestic borrowing with $c, b^{D}, b^{F}$ as control variables and $k_{p}, k_{g}, d^{D}$ and $d^{F}$ as state variables. 


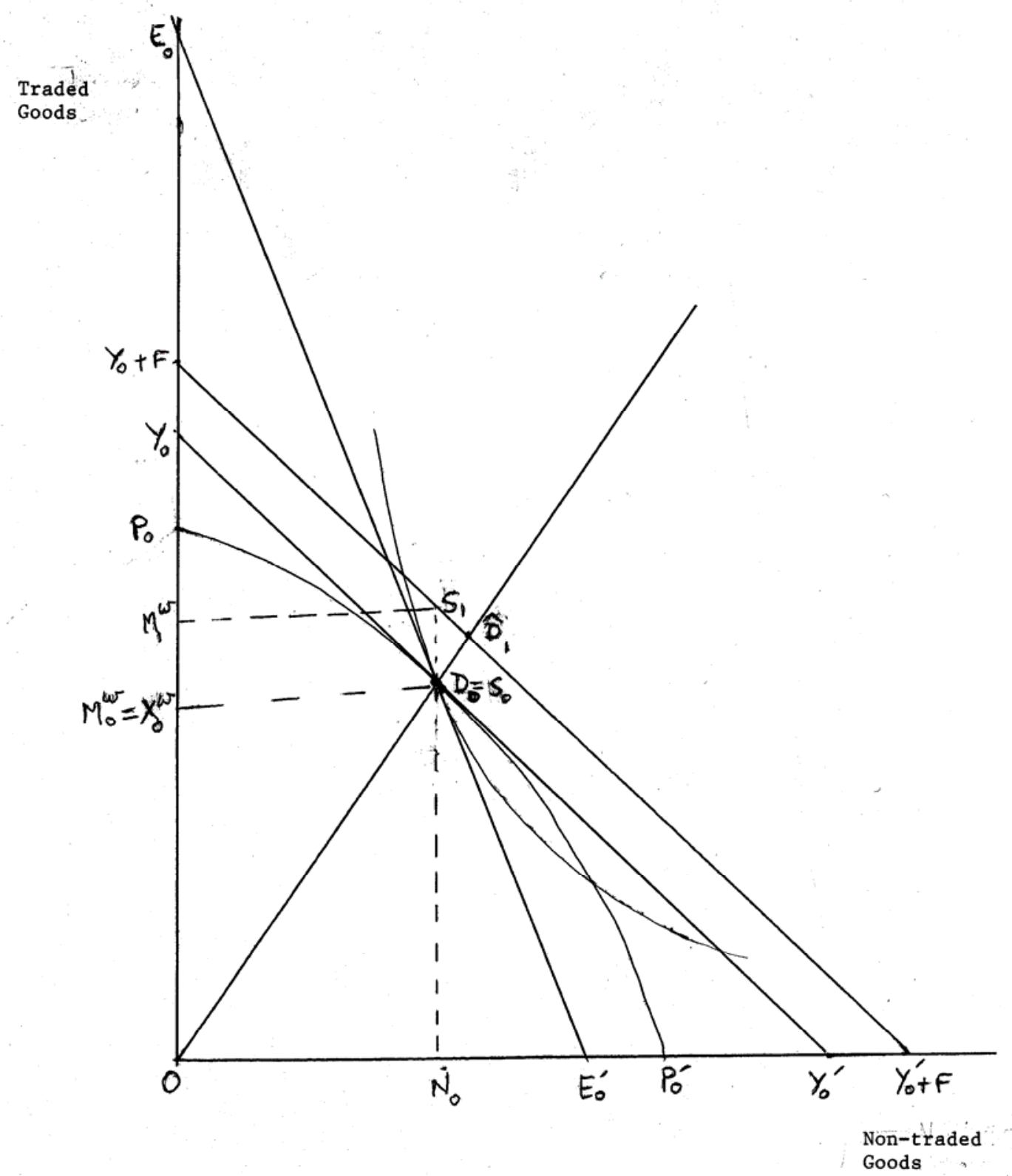

F1gure 1 


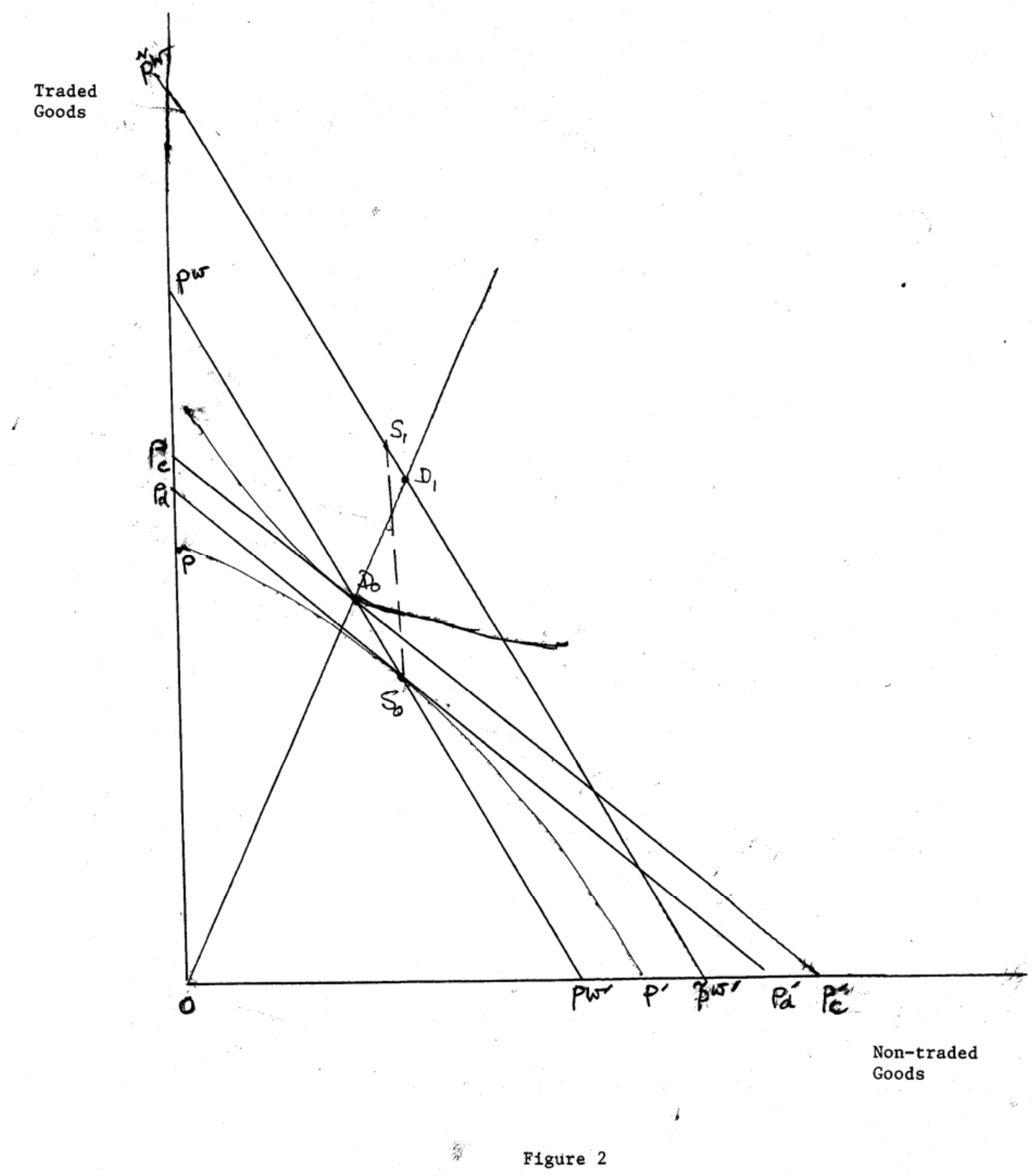

